\title{
Limitaciones legales para el desarrollo de la telesalud mental en el Perú.
}

\author{
Legal limitations for the development of telemental health in Peru.
}

\author{
Carlos Orellano ${ }^{1, a}$
}

\section{Estimados Editores:}

La pandemia del COVID-19 ha provocado la suspensión de diversas actividades tras la aplicación de la cuarentena en los países afectados sucesivamente, incluyendo el Perú. En el sector salud de nuestro país, los servicios asistenciales por consulta externa se han suspendido y sólo se limitan a la entrega de recetas para el tratamiento de aquellos pacientes continuadores con enfermedades crónicas tales como los trastornos en salud mental. El Ministerio de Salud, ante la necesidad de atender a la población, ha flexibilizado las normas legales respecto a la telesalud. Sin embargo, es preciso señalar que aún existen limitantes que restringen ciertas particularidades de cada especialidad, sobre todo en salud mental. A continuación, se explorará los cambios en la reglamentación y cómo va afectando a los servicios de telesalud mental.

Tanto la Norma Técnica en Salud del 2008 y la Ley Marco de Telesalud del 2016 con su respectiva modificatoria señalaban que la telemedicina (prestación de servicios en salud) está reservada para el personal de salud (1-3). Es así que quedaba restringida la posibilidad de que un usuario de salud pueda tener una consulta a distancia, como por ejemplo, con un médico psiquiatra. Además, especifican que la incorporación de las prestaciones de los servicios de telesalud se hace a través de los establecimientos de salud. Sin embargo, no se menciona si estas actividades puedan ejecutarse como parte de la práctica privada individual del profesional de salud.

Más adelante, se reitera esta única modalidad en telemedicina con la publicación del reglamento de la Ley en el 2019 bajo la definición de teleconsulta, en la que participa un personal de salud (quien solicita la teleconsulta, o teleconsultante) y un profesional de salud (quien responde a la teleconsulta, o teleconsultor), siendo opcional la presencia del paciente (4). Además, contempla tanto la toma de consentimiento informado y del consentimiento del tratamiento de datos personales.

A fines de marzo del 2020, aproximadamente dos semanas después de declararse el estado de emergencia y cuarentena a nivel nacional, el Ministerio de Salud aprueba la directiva relacionada a telemedicina síncrona y asíncrona (5). Dicho documento insta en la firma de los dos consentimientos referidos en el reglamento e incluye en sus anexos a los formatos para la toma de ambos con sus respectivas revocatorias.

También en esos días se aprueba la directiva sobre teleorientación y telemonitoreo (6). La primera se refiere a consejería y asesoría y, la segunda, a la transmisión de parámetros biométricos. Si bien estas nuevas definiciones responden principalmente a las intervenciones para prevención y detección de casos probables de infección por Covid-19, en la

1 Departamento Académico de Clínicas Médicas, Facultad de Medicina Alberto Hurtado, Universidad Peruana Cayetano Heredia. Lima, Perú.

a Docente; Médico psiquiatra; Magíster en Informática Biomédica. 
práctica se extrapoló para el seguimiento de pacientes continuadores en algunos centros de salud mental comunitarios y hospitales especializados en salud mental. Sin embargo, esto sería incompatible con lo señalado con esta nueva resolución ya que en la atención de seguimiento en psiquiatría se trata de examinar la evolución de los síntomas y realizar el examen mental, los cuales no pueden ser medidos por equipos. Por otro lado, los objetivos de la psicoterapia no se enmarcan en una simple orientación.

A mediados de abril, el Seguro Integral de Salud incorpora tanto a la teleorientación y telemonitoreo como parte de su tarifario, pero sólo las reconoce como tales si hay prescripción y entrega de medicamentos (7). Una vez más, se desvirtúan las definiciones dadas por la resolución del mes anterior. Además, no sería posible dar tratamientos farmacológicos mientras no existiera alguna directiva del mismo Ministerio de Salud que la reconozca como parte del acto médico en estas dos actividades. Pese a ello, los servicios de psiquiatría de algunos establecimientos proveyeron de recetas a sus pacientes continuadores. Por otro lado, este decreto no incluye a las intervenciones terapéuticas no farmacológicas. Así, en salud mental, los establecimientos de salud no recibirían retribuciones económicas por las telepsicoterapias realizadas por psiquiatras o psicólogos; provocando finalmente el desinterés de parte de los gestores por autorizar este tipo de servicios. Esta restricción también afectaría a otras posibles prestaciones como la telefisioterapia respiratoria, con potencial uso en el contexto actual frente a la carencia de profesionales.

En mayo del 2020, se publicó un nuevo decreto para fortalecer a la telesalud (8), la cual hace varias modificaciones a la Ley Marco de Telesalud, entre ellas, al artículo $3^{\circ}$ donde replantea la definición de teleconsulta, siendo definida en adelante como aquella consulta realizada entre un profesional de la salud y un usuario de salud. En consecuencia, estarían autorizadas las teleterapias, incluyendo la telepsicoterapia. Pero debe llamar la atención lo estipulado más adelante en el artículo 8 sobre la toma del consentimiento informado: a) no precisa cuáles son los servicios de telemedicina que lo exigen o las situaciones especiales que lo ameritan; y b) sólo reconoce a la firma manuscrita, a la firma electrónica avanzada $u$ otros medios autorizados por el Reglamento para tales fines. Sobre esto último, carecen de validez las firmas manuscritas escaneadas o la asociación con un usuario y contraseña. Como resultado de esta exigencia, sería escaso el número de teleconsultas atendidas porque la firma digital no ha sido masificada en la población peruana.

En conclusión, urge todavía la revisión de la normativa en telesalud y de las bases legales vinculantes para acercar este tipo de servicios a los usuarios sin que ello afecte sus derechos ni vulnere la seguridad de información. En telesalud mental queda pendiente por resolver si sería factible atender pacientes nuevos, tomando en cuenta las características de la primera entrevista y la complejidad psicopatológica. Tampoco existen guías que orienten el desarrollo de la teleconsulta ni cursos (presenciales, virtuales o híbridos) de capacitación con certificación, siendo de suma importancia para aquellos que brindan servicios en salud mental en donde la relación médico-paciente deberá ser construida con nuevas estrategias que superen las limitaciones de una evaluación a distancia. Finalmente, la continuidad de la telemedicina estará garantizada cuando se tenga información sobre la alfabetización digital en los profesionales y pacientes y así disponer de aplicativos con niveles de usabilidad adecuados.

\section{REFERENCIAS BIBLIOGRÁFICAS}

1. Ministerio de Salud. Norma técnica de salud en telesalud (NTS N ${ }^{\circ}$ 067-Minsa/DGSP-V.01). Lima: Ministerio de Salud; 2009.

2. Congreso de la República. Ley No 30421. Ley Marco de Telesalud. Lima: Diario Oficial El Peruano; 2016.

3. Presidencia de la República. Decreto Legislativo $\mathrm{N}^{\circ}$ 1303. Dicta disposiciones destinadas a optimizar los procesos vinculados a Telesalud. Lima: Diario Oficial El Peruano; 2016.

4. Ministerio de Salud. Decreto Supremo $N^{\circ}$ 0032019-SA. Aprueban el Reglamento de la Ley $\mathrm{N}^{\circ}$ 30421, Ley Marco de Telesalud modificada con el Decreto Legislativo No 1303, Decreto Legislativo que optimiza procesos vinculados a Telesalud. Lima: Diario Oficial El Peruano; 2015.

5. Ministerio de Salud. Resolución Ministerial $\mathrm{N}^{\circ}$ 117-2020-MINSA. Aprueban la Directiva Administrativa $\quad \mathrm{N}^{\circ} \quad$ 285-MINSA/2020/DIGTEL: Directiva para la implementación y desarrollo de los servicios de telemedicina síncrona y asíncrona. Lima: Diario Oficial El Peruano; 2020.

6. Ministerio de Salud. Resolución Ministerial $\mathrm{N}^{\circ}$ 146-2020-MINSA. Aprueban la Directiva Administrativa $\quad \mathrm{N}^{\circ}$ 286-MINSA/2020/DIGTEL: "Directiva Administrativa para la Implementación y Desarrollo de los Servicios de Teleorientación y Telemonitoreo". Lima: Diario Oficial El Peruano; 
2020.

7. Seguro Integral de Salud. Resolución Jefatural No 033-2020/SIS. Aprueban incorporación de los Códigos de Servicio 909 "Teleorientación con prescripción y entrega de medicamentos" y 910 "Telemonitoreo con prescripción y entrega de medicamentos", en el documento denominado
"Tarifario del Seguro Integral de Salud" y dictan diversas disposiciones. Lima: Diario Oficial El Peruano; 2020.

8. Presidencia de la República. Decreto Legislativo No 1490. Decreto Legislativo que fortalece los alcances de la Telesalud. Lima: Diario Oficial El Peruano; 2020. 